\title{
Peritonitis in Continuous Ambulatory Peritoneal Dialysis
}

Sharma SK,' Chaurasia RK, 'Sijapati MJ,' Thapa L,' Ghimire M, Shrestha H, ${ }^{1}$ Acharya A, ${ }^{2}$ Khanal B ${ }^{2}$ 'Department of Medicine, 'Department of Microbiology, BP Koirala Institute of Health Sciences, Dharan, Nepal.

\section{ABSTRACT}

Introduction: Access to hemodialysis is limited in Nepal due to geographical terrain and hemodialysis centers being mostly limited to major city. Therefore, continuous ambulatory peritoneal dialysis is likely to be a better option in Nepal. In 1998, CAPD was initiated in Nepal without success. High rate of peritonitis was cited for failure. Hot tropical climate and poor sense of hygiene among patients was thought to be responsible for the high rate of peritonitis. A new CPD program was started in 2002 in our institute. We reviewed the incidence of peritonitis and factors predisposing.

Methods: All chronic renal failure patients on CAPD since 2002 to 2007 were included in the study. They were followed up for complications and treatment outcome. Patients complicated with peritonitis $(\mathrm{N}=19)$ and patients without peritonitis $(\mathrm{N}=31)$ were compared.

Results: A total of 50 patients were enrolled and mean duration of dialysis was 12 month per patients (Total patients month=600). Twenty six episodes of peritonitis in 19 patients were recorded during this period. Fourteen episode of peritonitis were culture positive. Culture sterile peritonitis was recorded in 12 episodes. Low serum albumin was predisposing factors for peritonitis and peritonitis rate was higher in end stage disease related due to diabetes mellitus.

Conclusion: Peritonitis rate was comparable in our new program. Thus peritonitis is not a limiting factor for growth of CAPD in Nepal. Hypoalbuminemic and diabetic patients are prone for CAPD related peritonitis.

Key Words: Continuous ambulatory peritoneal dialysis, Peritonitis, Peritonitis rate.

Correspondence:

Dr. Sanjib Kumar Sharma

Department of Internal Medicine

B P Koirala Institute of Health Sciences

Dharan, Nepal.

Email: drsanjib@yahoo.com

Fax: 977-25-520251 


\section{INTRODUCTION}

Peritoneal dialysis (PD) is an important modality in the treatment of end-stage renal disease apart from hemodialysis and kidney transplantation. ${ }^{1}$ PD offers advantages like simplicity of the therapy, reduced need for trained manpower, minimal technical support and potential cost savings. ${ }^{2}$

One deterrent to choosing PD is higher morbidity and mortality associated with infection. ${ }^{3}$ The major infectious complications are peritonitis and tunnel infection. ${ }^{4}$ PD-associated peritonitis contributes significantly to morbidity and modality failure. ${ }^{1}$

Access to hemodialysis is limited in Nepal due to geographical terrain and lack of trained manpower, poor socioeconomic status in spite of huge burden of ESRD patients. ${ }^{5}$ Therefore; continuous ambulatory peritoneal dialysis (CAPD) is a better option of dialysis. In 1998, CAPD was initiated without success. High peritonitis rate was cited for failure. ${ }^{6}$ Hot climate and poor hygiene were thought to be responsible. The objective of this study was to find out the rate of peritonitis and predisposing factors in CAPD.

\section{METHODS}

A prospective observational study of all renal failure patients who were initiated on chronic peritoneal dialysis in Department of Medicine, BPKIHS from 2002 to 2007. Ethical approval was taken for the study. After proper counseling and education to family, CAPD was started and caretaker was trained for home peritoneal dialysis and also checked for proper technique and necessary precautions. Supportive medical treatments were continued and revised during follow up visits. CAPD nurses followedup these patients in nephrology clinics and during ward admission for any complications. The data were collected in a predesigned proforma. The CAPD nurses along with resident doctor in dialysis unit were responsible for the data recording.

Peritonitis was diagnosed if patient reported cloudy effluent and/or pain abdomen and had dialysate white cell count $>100 / \mathrm{mL}$ of which $50 \%$ or more were polymorphonuclear leukocytes. ${ }^{4}$ Confirmation of all episodes was attempted by microbiological culture of samples taken prior to antibiotic administration. Patients, who had exit site or tunnel infections in addition to peritonitis, were also included. The number of days until the first episode of peritonitis was determined from the day of initiation of CAPD until the onset of peritonitis, or until the end of the study period if there were no peritonitis episodes. ${ }^{7-10}$ All patients were on prophylactic mupirocine ointment. All the cases of CAPD associated peritonitis were admitted in medical ward initially and treated with intravenous antibiotics and outcome recorded and followed up.

The peritonitis rate was determined for all episodes of peritonitis. The peritonitis rate was calculated as the total number of episodes of peritonitis divided by total patient-months and was reported as either episodes/patient-month or episodes/n patient- months. ${ }^{1}$ Patients complicated with peritonitis $(\mathrm{N}=19)$ and patients without peritonitis $(\mathrm{N}=31)$ were compared by t-test for quantitative variables and by corrected Chi-square ${ }^{\left(X_{2}\right.}$ ) test for qualitative variables. The statistical calculations were done by using statistical package for social sciences (SPSS) version 11 for windows.

\section{RESULTS}

Total patient were 50 in this study. The mean age of our CAPD was 61.85 years. Most patients were male $(N=41)$. The Baseline characteristics of all patients have been shown in table-1. Mean duration of dialysis was 12 months per patient (Table 1). The total duration of follow-up was 600 patient-months. Nineteen patients developed peritonitis and 31 were free of peritonitis. Total episodes of peritonitis were 26 in 19 patients during this period. The rate of peritonitis was 4.33 episodes/patient-month or 4.33 episodes/100 patientsmonths. Fourteen patients had single episode of peritonitis where as 3 patients had two episodes and 2 patients had three episodes.

Table 1. Baseline characteristics of 50 ESRD patients on CAPD

\begin{tabular}{|c|c|c|c|}
\hline \multicolumn{2}{|l|}{ Characteristics } & Mean with \%/Range & SD \\
\hline \multicolumn{2}{|l|}{ Age(yrs) } & $61.86(42-81)$ & 9.508 \\
\hline \multicolumn{2}{|l|}{ Sex, Male } & $41(81)$ & - \\
\hline \multicolumn{2}{|c|}{ Duration of ESRD(month) } & $5.78(1-36)$ & 8.117 \\
\hline \multirow[t]{6}{*}{ Etiology of CKD } & Diabetes Mellitus & $31(62)$ & - \\
\hline & Hypertension & $12(24)$ & - \\
\hline & APKD & $2(4)$ & - \\
\hline & Chronic GN & $3(6)$ & - \\
\hline & Obstructive & & \\
\hline & nephropathy & $2(4)$ & - \\
\hline \multicolumn{2}{|l|}{ Co-morbidity } & $38(76)$ & - \\
\hline \multicolumn{2}{|c|}{ Systolic BP (mmHg) } & $145.76(80-250)$ & 26.853 \\
\hline \multicolumn{2}{|c|}{ Diastolic BP (mmHg) } & $88.96(70-130)$ & 14.033 \\
\hline \multicolumn{2}{|l|}{ GFR (ml/min) } & $8.269(3.78-12.8)$ & 2.4178 \\
\hline \multicolumn{2}{|c|}{ Haemoglobin (mg/dl) } & $9.254(4.6-13.5)$ & 2.2224 \\
\hline \multicolumn{2}{|c|}{ Serum albumin (mg/dl) } & $3.231(2.1-4.8)$ & 0.6456 \\
\hline \multicolumn{2}{|c|}{ Duration of CAPD (days) } & $353.48(14-1305)$ & 307.573 \\
\hline
\end{tabular}


Twenty patients expired during follow up and only 9 patients had history of peritonitis but only in 2 patients, the cause of death was due to consequence of peritonitis. Fourteen episodes of peritonitis were culture positive (staphylocoocus aureous-7, Psedomonous aurigonosae3, acinetobacter spp-3, streptococci-1). Culture sterile peritonitis was recorded in 12 episodes (patients).

Two patients in each group were shifted to hemodialysis therapy due to poor response with treatment for peritonitis.

All the possible predisposing variables such as age, duration of end stage disease at the starting of peritoneal dialysis, blood pressure, estimated glomerular filtration rate or creatinine clearance (by Cockcroft-Gault equation) at the onset of CAPD, blood hemoglobin, serum albumin, duration on CAPD, sex of patient, initial cause of kidney failure such as diabetes mellitus, hypertension or others and presence of co-morbidities such as hypertension, underlying ischemic heart disease for development of peritonitis were analyzed and shown in table $2 \mathrm{~A}$ and $2 B$ but only low serum albumin was statistically significant predisposing factors for development of peritonitis $(P$ value $<0.001$ ) and incidence of peritonitis was higher in end stage disease related due to diabetes mellitus than other causes $(41.9 \%)$ (Table 2,3$)$.

Table 2. quantitative variables comparison by t-test

\begin{tabular}{|c|c|c|c|c|}
\hline Variables & Peritonitis & Number & Mean \pm Std.Dev & $\mathrm{P}$ value \\
\hline \multirow[t]{2}{*}{ Age (yrs) } & Absent & 31 & $62.06 \pm 10.478$ & 0.976 \\
\hline & Present & 19 & $61.53 \pm 7.933$ & \\
\hline Duration of & Absent & 31 & $4.94 \pm 7.624$ & 0.353 \\
\hline ESRD (month) & Present & 19 & $7.16 \pm 8.902$ & \\
\hline
\end{tabular}

Sys BP

$\begin{array}{llllll}\text { (mmHg) } & \text { Absent } & 31 & 146.71 \pm 31.196 & 0.872 \\ & \text { Present } & 19 & 144.21 \pm 18.353 & \\ \text { Diastolic } & \text { Absent } & 31 & 89.94 \pm 14.380 & 0.667 \\ \text { BP }(\mathrm{mmHg}) & \text { Present } & 19 & 87.37 \pm 13.680 & \\ \text { GFR (ml/dl) } & \text { Absent } & 31 & 8.130 \pm 2.2397 & 0.472 \\ & \text { Present } & 19 & 8.497 \pm 2.7321 & \\ \text { Hemoglobin } & & & & \\ \text { (mg/dl) } & \text { Absent } & 31 & 9.284 \pm 2.4601 & 0.904 \\ & \text { Present } & 19 & 9.205 \pm 1.8314 & \end{array}$

Albumin

$\begin{array}{lllll}(\mathrm{mg} / \mathrm{dl}) & \text { Absent } & 31 & 3.294 \pm 0.687 & <0.001 \\ & \text { Present } & 19 & 2.432 \pm 0.338 & \end{array}$

Duration of

CAPD (days) Absent $31 \quad 420.03 \pm 260.26 \quad 0.296$

Present $\quad 19 \quad 499.89 \pm 258.40$
Table 3. Qualitative variables comparison by $\mathrm{X}^{2}$ test

\begin{tabular}{lllll}
\hline Variables & & Number & Peritonitis (\%) & P value \\
\hline Sex & Male & 41 & $17(41.5)$ & 0.485 \\
& Female & 9 & $2(22.2)$ & \\
Diabetic & & & & \\
nephropathy & Present & 31 & $13(41.935)$ & 0.666 \\
& Absent & 19 & $6(31.578)$ & \\
Hypertensive & & & & \\
nephropathy & Present & 12 & $3(25)$ & 0.470 \\
& Absent & 38 & $16(42.105)$ & \\
Co-morbidity & Present & 38 & $17(44.736)$ & 0.160 \\
& Absent & 12 & $2(16.666)$ &
\end{tabular}

\section{DISCUSSION}

Peritonitis is a common complication and sometimes a serious problem in patients undergoing continuous peritoneal dialysis and representing the most frequent cause of peritoneal catheter loss and discontinuation of PD. ${ }^{11-14}$ The high rate of peritonitis in 1977 was in large part attributable to the PD exchange systems and technique. Since the introduction of the Y-set, flushbefore-fill exit-site care, treatment Protocols, technology advances are a large contributor to the decline in peritonitis rates worldwide. The flush-before-fill technique was tested in vitro and was shown to remove $100 \%$ of Staphylococcus epidermidis, $60 \%$ of S. aureus, and $30 \%$ of Pseudomonas aeruginosa from tubing when flushed with $100 \mathrm{~mL}$ of fluid immediately after inoculation. ${ }^{15}$

In a review of seven randomized trials with a total of 485 patients, Maiorca and Cancarini ${ }^{16}$ reported a significantly lower risk of peritonitis with the $\mathrm{Y}$-set than with standard spike systems [RR: $0.64 ; 95 \% \mathrm{Cl}: 0.53$ to 0.77 ]. These authors also reviewed eight randomized trials comprising 7,417 patient- months and found a significantly lower rate of peritonitis with the $\mathrm{Y}$-set than with the standard spike (RR: $0.49 ; 95 \% \mathrm{Cl}: 0.40$ to 0.61 ).

The rate of peritonitis was 4.33 episodes/100 patient-months in our new program. Though it was higher than the other recent study but it is in decreasing trend also. The initial rate of peritonitis in 1977 was 5.8 episodes/patient-year. The initial high rate of peritonitis may be related to low education of patients, due to relatively new therapy, the awareness regarding CAPD, in many times mishandling of catheter during abdominal examinations leading to micro trauma and relatively poor follow-up that may resulted in decrease reinforcement of the preventive measures for infections. That rate gradually declined, so that by 2004 , the annual rate was 0.35 episodes/patient-year. This rate, 1 episode for every 34.3 patient-months, is lower than the recently reported average of 1 episode for every 25 patient-months ${ }^{17,18}$ and the peritonitis rate was 1 episode each 11.14 and 8.83 patient months, which was not significantly different in study done on Eighty-one patients 
Sharma et al. Peritonitis in Continuous Ambulatory Peritoneal Dialysis

with either on the O-set (39) or the UVXD germicidal system (42). ${ }^{19}$

In our study, the common cause of peritonitis is staphylococcal aureus and it is similar to organism pattern seen in study done by.${ }^{20}$ Most of the episodes of peritonitis are caused by touch contamination of the dialysis tubing or by extension of the catheter exit site or tunnel infection. Coagulase-negative and coagulase-positive staphylococci are the two most common organisms, accounting for $50 \%$ or more of all CAPD peritonitis. Other gram-positive and gram-negative bacteria and fungi account for the rest.

The mortality due to peritonitis is only in 2 cases out of 50 cases and which is similar to other causes of death in ESRD patients undergoing peritoneal dialysis. Peritonitis can be a significant cause of death in patients undergoing peritoneal dialysis. In one retrospective Spanish study of 565 patients, 41 of 693 episodes of peritonitis resulted in death (6 percent). ${ }^{21}$ Hypoalbuminemia was significantly associated with development of peritonitis and there was a high incidence of peritonitis in diabetes patients and it may be attributed due to impaired immune function in these patients in our study. Similar result ${ }^{22}$

\section{CONCLUSIONS}

The peritoneal dialysis modality offers an effective alternative to hemodialysis. Patients who are unable to undergo or to tolerate hemodialysis can choose to perform PD. Low serum albumin and diabetes patients are prone for CAPD related peritonitis. A robust and more studies are needed to support this finding in long term and to encourage CAPD in our set up.

\section{ACKNOWLEDGMENTS}

We sincerely acknowledge the contribution from dialysis nurses, technician and coordinator of CAPD and our patients who dedicated themselves to advancement of PD in Nepal.

\section{REFERENCES}

1 Whaley-Connell A, Pavey BS, Satalowich R, Prowant BF, Misra M, Twardowski ZJ, Nolph KD, et al. Rates of continuous ambulatory peritoneal dialysis-associated peritonitis at the University of Missouri. Adv Perit Dial. 2005;21:72-5.

2 Finkelstein FO, Abu-Aisha H, Najafi I, Lo WK, Abraham G, Pecoits-Filho R, Süleymanlar G. Peritoneal dialysis in the developing world: recommendations from a symposium at the ISPD meeting 2008. Perit Dial Int. 2009 Nov-Dec;29(6):618-22.

3 Bloembergen WE, Port FK, Mauger EA, Wolfe RA. A comparison of mortality between patients treated with hemodialysis and peritoneal dialysis. J Am Soc Nephrol. 1995 Aug;6(2):177-83.

4 Kathleen DL, Glenn MC. Dialysis in the treatment of renal failure. In: Harrison's principle of internal medicine 17th ed. New York: McGraw Hill Medical; 2008. p. 1772-5.

5 Sharma SK, Pahari B, Chaudhary S, Manadhar DN, Acharya PS, Agrawal R, et al. Initiation of Continuous ambulatory peritoneal dialysis in Nepal: Opportunities and Challenges. Indian J of Perit dial. 2009;16:8-11.

6 Sharma SK, Manandhar D, Singh S, Chauhan HS, Koirala B, Gautam M, et el. Acute Peritoneal Dialysis in Eastern Nepal. Perit Dial Int 2003;23(supp2):196- 199.

7 Bailie GR, Rasmussen R, Eisele G, Luscombe DK. Peritonitis rates in CAPD patients using the UVXD and O-set systems. Ren Fail. 1993;15(2):225-30.

8 Morse GD, Farolino DF, Apicella MA, Walshe JJ. Comparative study of intraperitoneal and intravenous vancomycin pharmacokinetics during continuous ambulatory peritoneal dialysis. Antimicrob Agents Chemother. 1987 Feb;31(2):173-7.

9 Dharmasena D, Roberts DE, Coles GA, Williams JD. Pharmacokinetics of intraperitoneal ciprofloxacin in patients on CAPD. J Antimicrob Chemother. 1989 Feb;23(2):253-9.

10 Paton TW, Manuel A, Cohen LB, Walker SE. The disposition of cefazolin and tobramycin following intraperitoneal administration in patients on continuous ambulatory peritoneal dialysis. Perit Dial Int. 1983;3:73-6.

11 Holley JL, Piraino BM. Complications of peritoneal dialysis: Diagnosis and management. Semin Dial. 1990;3:245-8.
12 Schreiber M, Burkart JM, et al. Peritonitis remains the leading cause of transfer from PD to HD (abstract). Perit Dial Int $1996 ; 16: 217$

13 Woodrow G, Turney JH, Brownjohn AM. Technique failure in peritoneal dialysis and its impact on patient survival. Perit Dial Int. 1997;17:360.

14 Guo A, Mujais S. Patient and technique survival on peritoneal dialysis in the United States: evaluation in large incident cohorts. Kidney Int Suppl. 2003 Dec;(88):S3-12.

15 Verger C, Luzat MA. In vitro study of CAPD, Y-line systems. Adv CAPD. 1986; 2:160-4.

16 Maiorca R, Cancarini G. Thirty years of progress in peritoneal dialysis. J Nephrol. 1999 Jul-Aug;12 Suppl 2:S92-9.

17 Krishnan M, Thodis E, Ikonomopoulos D, et al. Predictors of outcome following bacterial peritonitis in peritoneal dialysis. Perit Dial Int. 2002;22:573-81.

18 Fielding RE, Clemenger M, Goldberg L, Brown EA. Treatment and outcome of peritonitis in automated peritoneal dialysis, using a once-daily cefazolin based regimen. Perit Dial Int. 2002;22:345-9.

19 Bailie GR, Rasmussen R, Hollister A, Eisele G. Incidence of CAPD peritonitis in patients using UVXD or O-set systems. Clin Nephrol. 1990 May;33(5):252-4.

20 . CAPD peritonitis: Incidence, pathogens, diagnosis, and management. Med Clin North Am 1990 Jul;74(4):997-1010.

21 Fontan MP, Rodriguez -Carmona A, Garcia-Naveiro R, et al. Peritonitis related mortality in patients undergoing chronic peritoneal dialysis. Perit Dial Int. 2005;25:274.

22 Abraham G, Mathew M; Gopalakrishnan P; Sankarasubbaiyan S; Shroff S. Are three exchanges suitable for Asian patients on peritoneal dialysis? Perit Dial Int. 2003;23 Suppl (2):545-7. 